re-established in Shillong. The Southern Circle has been re-created; but map publication is still largely concentrated in Dehra Dun, where also the projects officer is located. No new or revision topographical surveys or forest surveys were carried out during the year ; but two settlement surveys were undertaken in the hilly districts of Kulu and Almora. Considerable progress has been made in replenishing stocks of quarter-inch maps corrected up to date ; but for oneinch maps the present policy is to reprint the maps uncorrected pending the opportunity for surveying the necessary corrections. The series comprises 4,100 sheets, and in issuing corrected editions a start will be made with the most developed regions.

War experience as well as post-war activities have shown the need for a strong scientific body largely free from administrative responsibilities to enable the Survey of India to keep abreast of scientific thought and developments. The proposed Survey Research Institute, replacing the War Survey Research Institute, when constituted, will carry out the scientific functions of the Survey, and will also collaborate with the National Physical Laboratory, particularly in respect of standards of length and time. The Institute will be staffed and organised for work on measurements of length ; standardization of measuring tapes, etc. ; astronomical work as applied to latitude, longitude and time; tidal work; and magnetic observations. During the year the War Survey Research Institute carried out further investigations on the improvement of base-measurement apparatus and devised new methods of rapid fixation of pqition from stellar observations.

\section{Linen Research Association : Report for 1948}

THE Linen Research Association, which is at Lambeg, Co. Axtrim, has recently issued its annual report for the wor ended September 30, 1948. The report reconas the opening of the new buildings in $J$ fe 3 installation of plant and equipment in th f new technical shed for bleaching, dyeing and firtshing is now almost complete. Delivery of machinery for the weaving section has also begun; but difficulties in recruiting well-qualified scientific staff have continued, although the accommodation for the increased staff planned in 1945 is now available. In view of the fall in home flax production, it is considered essential to continue research on flax production and to make another serious attempt to increase the yield of flax obtained from scutching. The total number of members is now 280 , and the report includes lists of both members and staff and of the membership of committees. Research work carried out during the year has included a continued study of the effect of varying the retting process on the yield and quality of fibre produced from different types of straw, and also a study of the prevention of deterioration of the retted straw during drying. An investigation on a standard turbine scutchingmachine has shown that low humidity has little effect on yield provided the straw contains about 14 per cent of moisture, but it greatly reduces the yield if the straw is dry; while at $85-90$ per cent relative humidity in the turbine, dry straw can be scutched with a yield only slightly lower than that with properly conditioned straw. The investigation for the Ministry of Supply on the relation between fibre properties and yarn quality has been completed, and an investigation of 'dropped ends' has been started to determine the factors which limit the rate of production and the efficiency of spinning frames.
Weaving tests have continued on a variety of yarns in automatic looms of the shuttle-change and pin. change types. Work on cloth bleaching has aimed at modifying existing processes to whiten fabrics with no degradation of the cellulose, and to secure the maximum durability; while work on dyeing has led to an improved method of securing penetration of vat dyes in linen fabrics.

\section{Analysis of Management}

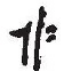

IN his paper, "The Nature of Management", based on an address to the London and District Society of Chartered Acqotutants, and now issued as "Occasional Papers No/ $2 m^{\prime}$ by the British Institute of Management. Siry Charles Renold insists that management is Grideted to action and that the action is at second. hafd : management is concerned with guiding the actions of people other than the planners or guiders. Accordingly he regards management as fundamentally the process of getting things done through the agency of a community, and the functions of management as the handling of a community with the view of its ful. filling the purposes for which it exists. A large part of those functions is, in fact, concerned with the well-being of the team or community, and, in pursuing that well-being, the particular purpose of the com. munity may be only of very indirect consideration. Sir Charles examines in some detail the requirements of community well-being so far as they are yet understood, emphasizing the importance not only of the structure or organisation of the community and procedures but also of their acceptance by the individuals forming the community. Contentment will not be secured unless there is confidence that rules and discipline are administered fairly, and the processes of using the team or community to achieve its purposes really turns on devising instructions appropriate to the situation. Planning he regards as a group of processes providing the raw material from which operative instructions are fashioned, and control as seeing how the plans are working out with the view either of modifying them or of improving the response of the community when necessary. Account. ancy is one of the indispensable techniques of management; but he points out that every official in the course of his executive duties has to make decisions which are of the nature of policy, and the readiness to accept responsibility for making such decisions and the ability to make wise ones are as important elements in the qualifications of an official as is loyal compliance with orders. The statement that policy-making is the business of the board of directors and execution that of the management should not be accepted uncritically; and Sir Charles distinguishes policy-making as the establishment (not necessarily the origination) of an overall pattern of rules and principles from the development of these rules and principles into greater detail, and execution as their application to particular situations.

\section{Problems in Astronomy 19}

THE Cawthronflecture for 1947, with the title of "Problems in Astronomy, Solved and Unsolved", was delived d by F. G. Gibbs, curator of the Atkinson obser atory, Nelson, N.Z., and gives a very useful sunfey of the progress of astronomy during the las two decades. Some space is devoted to an examination of the theories of the source of stellar energy, and a short description' is given of Bethe's carbon-cycle theory which is now generally accepted. A consideration of variable stars leads to the past 
history of the sun, the heat of which has been shown by geological evidence to have varied considerably during the last 1,000 million years. Simpson's pluvial theory is dealt with-a theory which assumes that increased precipitation of moisture in the form of rain and snow was due to an increase in the heat of the sun-but no satisfactory explanation has yet been given of the cause of the variation in the sun's heat. Regarding novæ and super-novæ, no explana. tion is suggested beyond the statement that "atomic energy has no doubt something to do with it". Among some of the problems still awaiting solution are the origin of the solar system, the evolution of the stars, the structure and evclution of the universe, and cosmic rays. This lecture provides a very helpful summary of the progress of astronomy in compara. tively recent times and also of the problems still awaiting solution, some of which appear more intractioble now than they did twenty years ago.

Royal Scottish Museum : Natural History Department

WrTH the refopenting of the Beasts of Prey Hall, the main halls of galleries belonging to the Natural History Pfpartment of the Royal Scottish Museum, Edin furgh, are now available to the public. These number twelve in all, allocated as follows: British fauna (2), mammals (3), extinct animals (1), foreign birds (1), amphibians and reptiles (1), fishes and molluses (1), entomology (1), biology (1), and children's gallery (1). In addition, the study room, for use of students of the collections, is now open. During the War, many of the collections were removed, and the opportunity has now been taken to re-arrange much of the material. In addition, two specialist galleries for students are in use. An introductory hall entitled "The Story of the Earth", serving as an introduction to natural history and geology, is in course of preparation. A gallery of maring invertebrates is projected.

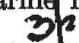

Univertal Decimal Classification

THE first abridgment of the full universal decimal elassification in English has been published by the British Stan do buds' Institution as B.S. 1000 A. : 1948. It confstsp 128 pages and costs $25 s$. It is intended fo th libraries or private collections where dyouled subdivision of subjects is not required, or in special libraries using the full classification in a given subject but requiring an abridged classification for other fields. It is based on the official abridgment in the Dutch language, fifth edition, with the help, mainly in the sciences, of the abridgment published by H.M. Stationery Office, under the title "Classification for Works in Pure and Applied Science in the Science Museum Library", third edition. The abridgment should form a useful introduction and guide to the complete fourth edition in English, which is being published by the British Standards Institption, section by section.

\section{Correction of Magnesium Deficiency in Tomatoes}

MAGNESIUM chlogesis is widespread among tomatoes grown unferasis in Great Britain. It probably cayses a ofnsiderable loss of yield, and economic meshods for its correction are therefore urgently rechired. D. J. D. Nicholas shows (J. Hort. Sci., 24, No. 1,1-18; June 1948) that this can best be accomplished by sprays of two per cent of magnesium sulphate applied to the foliage five times at intervals of two or three weeks. This results in the application of less than 5 cwt. per acre, compared with 10-20 cwt. of calcined kieserite, found necessary for soil applications. Soil factors probably immobilize a large proportion of the soil dressings of magnesium sulphate. Interactions of magnesium with potassium and nitrogen are also discussed in the paper.

\section{Chelsea Polytechnic}

THE fifty-third annual report of Chelsea Polytechnic is intg because of the attractive way in which Hafoms have been presented. Besides the usual information about the number and range of clafs ds and examination successes, the report contains a tetailed analysis of the occupations of evening students, the geographical distribution of students, the kind of research undertaken by advanced students and particulars of services rendered by members of the staff in a voluntary capacity to various kinds of learned and other societies. The examination statistics show that, during the last two years, one D.Sc., five Ph.D.s and seventeen M.Sc.s were obtained, figures of considerable significance for those who wish to see some evidence that the recommendations of the Percy Committee on Higher Technological Education have not been forgotten. This report, so clearly and precisely presented, is a fine example of what such a document can be in building up the corporate spirit of a large institution.

New Zealand Earthquakes during October 1948

NINE strong distant earthquakes were registered during Ogtol 1948 by the New Zealand seismograph s. Stated at Auckland, Arapuni, Christchurch, Kaimat?, New Plymouth, Tuai and Wellington, according to the report from the Dominion Observatory, Wellington. In addition, eighteen earthquakes and tremors were felt by people in New Zealand during the month. The greatest of these had instrumental strength $4 \frac{1}{2}$ and was felt at Dunedin and Monowai on October 9 . The next most intense had instrumental strength $4 \frac{1}{4}$, and these were felt on October 16 at Otaki and Wanganui, and on October 29 at Hanmer Springs.

\section{Editorial Board of Chymia}

The Unilersity of Pennsylvania Press has announced the appointment of Henry M. Leicester, professor of biochemistry, College of Physicians and Surgeons in San Francisco, as editor-in-chief of Chymia : Annual Studies in the History of Chemistry. Dr. Leicester, who succeeds the late Tenney L. Davis as editor, is chairman of the History of Chemistry Division, American Chemical Society, and associate editor of the Journal of Chemical Education. Prof. John Read, professor of chemistry and director of the Chemistry Research Laboratory, University of St. Andrews, is the new associate editor of Chymia. Other members of the editorial board are : Claude $K$. Deischer, Rudolf Hirsch, Herbert S. Klickstein and Eva V. Armstrong.

\section{University of Lohdon: Appointments}

THE following announcements of appointments have recently boen issued: Prof. H. C. Darby has accepted an invjation to the University chair of geography tenable at University College, and Mr. W. O. Lester Snath to the University chair of sociology of education tenable at the Institute of Education, both as from October 1, 1949. Dr. P. E. Vernon has been appointed to the University chair of educational psychology tenable at the Institute of Education, as 